\title{
Discovering novel zoonotic viruses
}

\section{Lin-Fa Wang}

CSIRO Livestock Industries, Australian Animal Health Laboratory

Email: linfa.wang@csiro.au

\begin{abstract}
From the emergence of Hendra virus and Menangle virus in Australia to the global pandemics of severe acute respiratory syndrome and influenza viruses (both H5N1 and H1N1), there has been a surge of zoonotic virus outbreaks in the last two decades. Although the drivers for virus emergence remain poorly understood, the rate of discovery of new viruses is accelerating. This is due to a combination of true emergence of new pathogens and the advance of new technologies making rapid detection and characterisation possible. While molecular approaches will continue to lead the way in virus discovery, other technological platforms are required to increase the chance of success. The lessons learnt in the last 20 years confirm that the One Health approach, involving inclusive collaborations between physicians, veterinarians and other health and environmental professionals, will be the key to combating future zoonotic disease outbreaks.
\end{abstract}

Globalisation of travel and trade, changes in agricultural practice (e.g. intensive farming and land use) and climate change are some of the drivers responsible for the emergence of novel pathogens affecting humans and livestock. ${ }^{1}$ Early detection and/or identification of the causative agent plays a pivotal role in minimising the impact of any infectious disease outbreak, especially for those caused by previously unknown pathogens. This review describes some of the recent zoonotic viral disease outbreaks both in Australia and abroad and focuses on the approaches and impact of virus discovery during disease investigation. It also summarises current virus discovery strategies and future trends in this area. While this review focuses on the importance of molecular techniques in virus discovery, it should be emphasised that virus isolation and serological investigation is equally important in the investigation of diseases caused by previously unknown viruses.

\section{A brief review of virus discovery with or without associated diseases \\ Hendra virus}

In September 1994, a mysterious disease outbreak, with primarily respiratory presentation, occurred in a horse stable in Hendra, Brisbane. It claimed the life of the horse trainer and 13 of his high value horses. A stable hand on the property also suffered a severe respiratory illness, but survived the infection. Three days after receiving horse specimens at the CSIRO Australian Animal Health Laboratory, cytopathic effect was observed in cultures of Vero cells inoculated with lung homogenates from deceased horses. Similar results were observed with human specimens a few days later. Electron microscopic analysis indicated the presence of a viral agent with a morphology resembling paramyxovirus. Further polymerase chain reaction (PCR) analysis using degenerate primers demonstrated a partial sequence of the matrix protein gene most similar to the cognate genes of morbilliviruses in the family Paramyxoviridae. A challenge experiment conducted under stringent biocontainment conditions at the CSIRO Australian Animal Health Laboratory demonstrated that the isolated virus was able to kill horses 4-5 days after infection and a similar clinical presentation, and the virus was re-isolated from infected animals, fulfilling all four requirements of the original Koch's postulate. Hendra virus was therefore the causative agent of the zoonotic viral disease outbreak. ${ }^{2}$ About a year later it was determined that flying foxes are the natural reservoir of this novel virus. ${ }^{3}$ Since 1994, there have been 14 recorded Hendra virus outbreaks, together responsible for the death of more than 40 horses and four humans.

\section{Nipah virus}

From late 1998 to early 1999 in peninsular Malaysia, an unusual surge of encephalitic disease was detected in people dealing with live pigs. The incidents coincided with outbreaks of respiratory disease in pigs. A novel virus was isolated from human patients, which was closely related to the Hendra virus. ${ }^{4}$ It was named Nipah virus after the name of the village of the index case, and later proved to be the causative agent of both the human and pig disease. It is now known that different strains of Nipah virus are widely distributed in bats from Indonesia, Malaysia, Thailand, India, Bangladesh, Madagascar and west African nations. ${ }^{5}$ Since the Malaysian outbreaks, Nipah virus has emerged almost annually in Bangladesh. In total, the virus has claimed the lives of more than 250 humans with mortality rates ranging from 40 to $100 \%$.

To confirm that Nipah virus also uses bats as its natural reservoir, field surveillance studies were carried out to detect virus in bat urine on Tioman Island in Malaysia. 
In addition to the isolation of Nipah virus, two new viruses were discovered: Tioman virus (a paramyxovirus) and Pulau virus (a reovirus). The significance of these 'accidental' discoveries will be explored later in this paper.

\section{Menangle virus}

Menangle virus was isolated in 1997 from stillborn piglets with deformities at a large commercial piggery in New South Wales. ${ }^{6}$ The virus was found to be responsible for a single outbreak of reproductive disease, causing reduced farrowing rate and stillbirths with deformities. Serum samples from two humans, who were in close contact with infected pigs and suffered a flu-like illness, were found to have high levels of convalescent neutralising antibodies to Menangle virus. Extensive serological testing showed no evidence of any alternative cause. It is believed therefore that the human illness was caused by Menangle virus, demonstrating a zoonotic potential that is yet to be fully characterised. Although the exact origin of the virus was not known at the time of the outbreak, serological studies indicated the presence of neutralising antibodies in bats. The bat origin was further corroborated by comparative genome sequencing, which indicated that the Menangle virus is highly related to the batborne Tioman virus identified in Malaysia. $^{7}$

\section{SARS virus}

The severe acute respiratory syndrome (SARS) coronavirus was responsible for the first serious and widespread zoonotic disease outbreak of the 21 st century, having a huge global impact on health, travel and economy. ${ }^{8}$ The great global impact of the SARS outbreak was in some ways intensified by the delay in identifying the causative agent of the disease. From November 2002, a mysterious disease known as 'atypical pneumonia' was rapidly spreading in southern China, exacerbated by several intensive nosocomial transmissions. It took almost 6 months before a novel coronavirus was isolated by the joint effort of the WHO SARS Collaborative Network. ${ }^{8}$ Within a few weeks of virus identification, the whole genome sequence was determined. This in turn facilitated the development and distribution of molecular and serological tests which played an essential role in the eventual control of the global pandemic. It is important to note that the global outbreak was under control within 3 months of the discovery of the causative agent. The genomic sequence information also played an important role in the identification of civets as the main intermediate host responsible for transmitting the virus to humans and bats as a potential natural reservoir of the SARS virus and other highly related coronaviruses. ${ }^{8,9}$

\section{Melaka virus}

Reoviruses (respiratory enteric orphan viruses) were first discovered in the 1950s and named orphan viruses due to the failure to associate them with any known human disease. As mentioned previously, Pulau virus was isolated during a search for Nipah virus in bat urine samples, which is closely related to Nelson Bay virus isolated from Australian bats in the early 1970 s. ${ }^{10}$ The disease-causing potential of neither virus was known. In 2006, during an investigation of a small cluster of patients in a Malaysian family suffering from severe flu-like symptoms, a virus was isolated and named Melaka virus. Electron microscopic examination revealed a reovirus-like structure. Using the sequence information and reagents developed for Pulau and Nelson Bay viruses, rapid confirmation of Melaka virus as a zoonotic reovirus was achieved within 2 weeks. Melaka virus represents the first reovirus known to cause severe acute disease in humans. Since then, at least two additional bat reoviruses have jumped species to infect humans and cause respiratory disease. ${ }^{11}$

\section{A new arenavirus}

In 2008, three Australian recipients of a visceral organ transplant from a single donor died of a febrile illness 4-6 weeks after transplantation. Due to the nature of the disease, involvement of an infectious agent was suspected. However, bacterial and viral culture revealed no candidate pathogens. PCR assays for most known human viral and bacterial pathogens, and pan-viral and pan-microbial oligonucleotide microarray analyses also failed to identify any potential agent. Eventually, the causative agent was identified by unbiased high-throughput sequencing. ${ }^{12}$ Out of 103632 sequencing reads obtained from total RNA extracted from different organ tissues of two patients, 14 sequences were shown to be related to Old World arenaviruses, with lymphocytic choriomeningitis virus being the most related. Subsequent virus isolation from frozen kidney samples was successful. While not all of Koch's postulate conditions were fulfilled, the fact that all four patients (donor and three recipients) had virusspecific antibodies and all recipients had viral RNA in their circulation was considered compelling evidence that the arenavirus was the cause. ${ }^{12}$

\section{Reston Ebola virus}

Ebola viruses are members of the family Filoviridae associated with acute fatal haemorrhagic diseases of humans and non-human primates. Among the five known species of Ebola viruses, Reston Ebola virus is the only one thus far not associated with disease in humans although nonsymptomatic infection has been observed in humans in the United States and Philippines. Recently it has been shown that African fruit bats are the likely natural host of the African species of Ebola virus. It is not known whether this is also the case for Reston Ebola virus, so far only detected in non-human primates in the Philippines. During an investigation for respiratory and reproductive disease syndrome in domestic pigs in the Philippines, multiple cell 


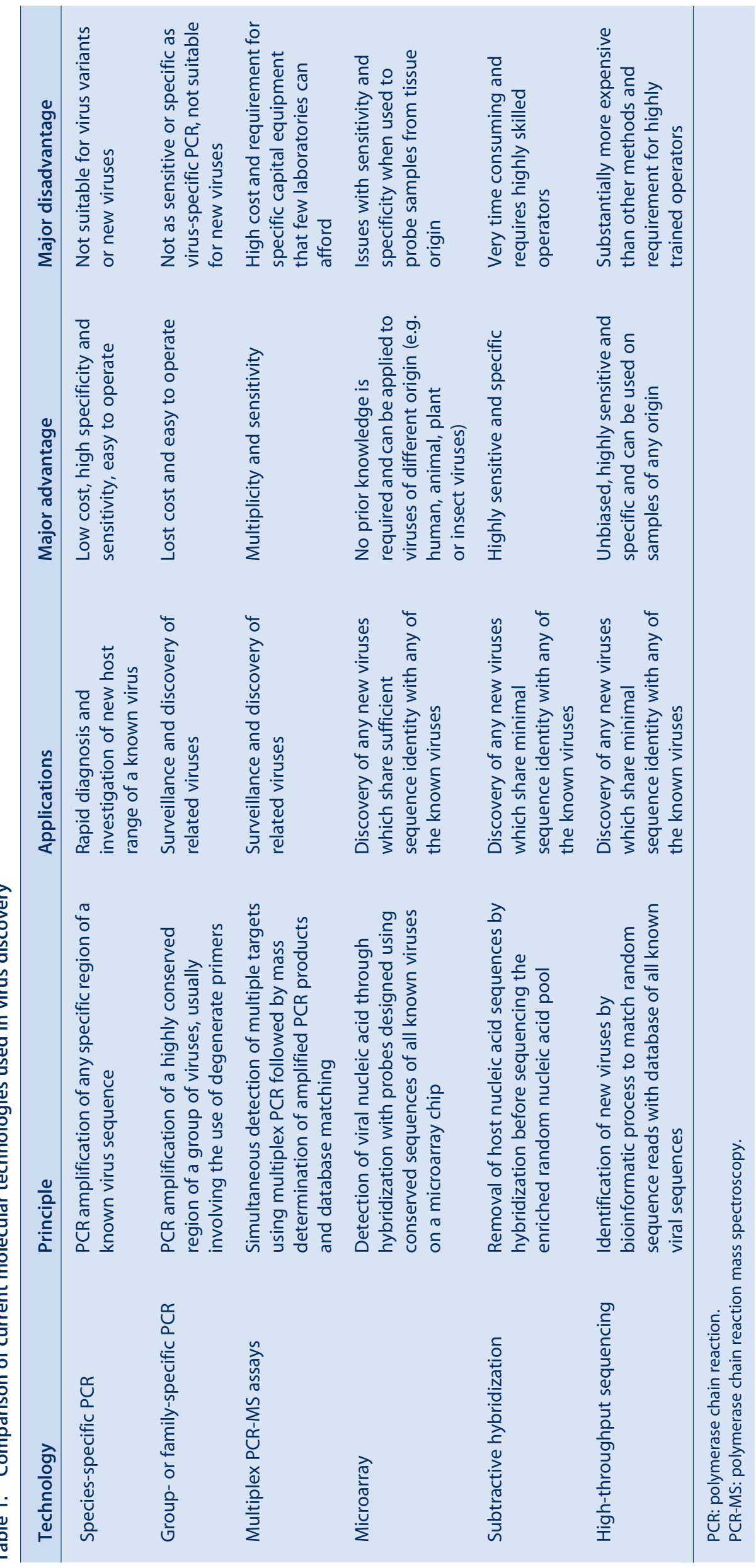


lines were used for virus isolation. In addition to the isolation of the porcine reproductive and respiratory syndrome virus, which was the main suspected causative agent, cytopathic effect was unexpectedly detected in Vero cells which are nonpermissive to the porcine virus. To investigate the identity of this virus, viral nucleic acid materials were tested using a pan-viral microarray. It was revealed that this unknown agent was the Reston Ebola virus. ${ }^{13}$ This is a highly significant discovery, widening the host range of Ebola virus to domestic pigs. Of the 141 individuals who worked on pig farms or with swine products, six had Ebola-specific antibodies, confirming pig-to-human transmission. ${ }^{13}$

\section{Different pathways to virus discovery}

The examples of virus discovery reviewed in this paper were selected to highlight two points: (1) most are associated with bats; and (2) virus discovery goes beyond finding previously unknown viruses: it is equally important to discover related viruses or new hosts of known viruses.

Although most of the discoveries of new viruses were made as a result of disease investigation, there are also examples where orphan viruses were 'accidentally' discovered, and later proved to be highly useful in the investigation of disease outbreaks caused by viruses closely related to them. Faced with the rapid technology advances in virus discovery, it is expected that more and more orphan viruses will be discovered. The appropriate sharing of orphan virus reagents and information in the international community will be crucial for effective future responses to infectious disease caused by novel viruses.

It should also be noted that the causal relationship between a virus and disease may be established by modern technologies without fulfilling all four conditions specified in the original Koch's postulates. ${ }^{14}$ This was best illustrated by the description of the identification of a new arenavirus as the causative agent of a disease that resulted in the deaths of three transplant patients from the same donor. ${ }^{12}$

\section{Increasing importance of molecular approaches to virus discovery}

It is evident from all the cases reviewed in this paper that molecular techniques played a pivotal role in the discovery of new viruses. The various molecular techniques currently being used for virus discovery are summarised in Table 1. While virus-specific PCR is a powerful tool for diagnosis and investigation of new host ranges of known viruses, its usefulness in the discovery of new viruses is rapidly being superseded by more advanced molecular technologies. Multiplex PCR-MS (mass spectroscopy) assays such as the Ibis T500 biosensor system ${ }^{15}$ and the MassTag PCR ${ }^{16}$ are extremely powerful tools for investigating multiple microbe targets, ${ }^{17}$ however very few laboratories can afford the high cost equipment required. Microarrays containing oligonucleotide probes to all known viruses were at one stage considered the future of virus discovery, ${ }^{18,19}$ but their performance has not met initial expectations due to issues with sensitivity and specificity when tissue samples are used. Currently, the most powerful and promising method of rapid agent identification is the unbiased highthroughput sequencing strategy. ${ }^{12,17}$ Although currently expensive, its application is expected to increase and with this the cost will decrease. Also, consideration of its speed (within days) and definitive nature will likely outweigh the cost, especially during the investigation of emergency disease outbreaks. The success rate of virus discovery in raw tissue samples can be increased by combining subtractive cDNA hybridization ${ }^{7}$ and high-throughput sequencing.

\section{Conclusion}

The most advanced molecular tools described in this paper are available in only a small number of specialised laboratories around the world. Their effective application is therefore dependent on close international collaboration and networks involving both human and animal health professionals, and laboratories in both developed and developing nations. Technology advance in other areas will also play a role in shaping the future of virus discovery; these include the development of more efficient sequence data management and bioinformatics tools, the development of specialised cell lines to increase the chance of successful isolation of live viruses, ${ }^{20}$ and the development of high density protein or peptide arrays for serological examination of antibodies cross-reactive with highly conserved epitopes of all known viral proteins. ${ }^{17}$

\section{Acknowledgments}

The virus discovery work conducted in the author's group is mainly funded by the Australian Cooperative Centre for Emerging Infectious Diseases and a CSIRO OCE Science Leader Award. I thank Gary Crameri and Glenn Marsh for critical reading of the manuscript.

\section{References}

1. Morse SS. Factors in the emergence of infectious diseases. Emerg Infect Dis 1995; 1(1): 7-15. doi:10.3201/eid0101.950102

2. Murray K, Selleck P, Hooper P, Hyatt A, Gould A, Gleeson L et al. A morbillivirus that caused fatal disease in horses and humans. Science 1995; 268(5207): 94-7. doi:10.1126/ science. 7701348

3. Young PL, Halpin K, Selleck PW, Field H, Gravel JL, Kelly MA et al. Serologic evidence for the presence in Pteropus bats of a paramyxovirus related to equine morbillivirus. Emerg Infect Dis 1996; 2(3): 239-40. doi:10.3201/eid0203.960315

4. Chua KB, Bellini WJ, Rota PA, Harcourt BH, Tamin A, Lam SK et al. Nipah virus: a recently emergent deadly paramyxovirus. Science 2000; 288(5470): 1432-5. doi:10.1126/science. 288.5470 .1432 
5. Hayman DT, Suu-Ire R, Breed AC, McEachern JA, Wang L, Wood JL et al. Evidence of henipavirus infection in West African fruit bats. PLoS ONE 2008; 3(7): e2739. doi:10.1371/ journal.pone.0002739

6. Philbey AW, Kirkland PD, Ross AD, Davis RJ, Gleeson AB, Love RJ et al. An apparently new virus (family Paramyxoviridae) infectious for pigs, humans, and fruit bats. Emerg Infect Dis 1998; 4(2): 269-71. doi:10.3201/eid0402.980214

7. Chua KB, Wang LF, Lam SK, Crameri G, Yu M, Wise T et al. Tioman virus, a novel paramyxovirus isolated from fruit bats in Malaysia. Virology 2001; 283(2): 215-29. doi:10.1006/ viro. 2000.0882

8. Peiris JS, Guan Y, Yuen KY. Severe acute respiratory syndrome. Nat Med 2004; 10(12S): S88-97. doi:10.1038/nm1143

9. Li W, Shi Z, Yu M, Ren W, Smith C, Epstein JH et al. Bats are natural reservoirs of SARS-like coronaviruses. Science 2005; 310(5748): 676-9. doi:10.1126/science.1118391

10. Pritchard LI, Chua KB, Cummins D, Hyatt A, Crameri G, Eaton BT et al. Pulau virus; a new member of the Nelson Bay orthoreovirus species isolated from fruit bats in Malaysia. Arch Virol 2006; 151(2): 229-39. doi:10.1007/s00705-005-0644-4

11. Chua KB, Crameri G, Hyatt A, Yu M, Tompang MR, Rosli J et al. A previously unknown reovirus of bat origin is associated with an acute respiratory disease in humans. Proc Natl Acad Sci USA 2007; 104(27): 11424-9. doi:10.1073/pnas.0701372104

12. Palacios G, Druce J, Du L, Tran T, Birch C, Briese T et al. A new arenavirus in a cluster of fatal transplant-associated diseases. N Engl J Med 2008; 358(10): 991-8. doi:10.1056/ NEJMoa073785
13. Barrette RW, Metwally SA, Rowland JM, Xu L, Zaki SR, Nichol ST et al. Discovery of swine as a host for the Reston ebolavirus. Science 2009; 325(5937): 204-6. doi:10.1126/ science. 1172705

14. Rivers T. Viruses and Koch's postulates. J Bacteriol 1937; 33(1): $1-12$.

15. Sampath R, Hall TA, Massire C, Li F, Blyn LB, Eshoo MW et al. Rapid identification of emerging infectious agents using PCR and electrospray ionization mass spectrometry. Ann N Y Acad Sci 2007; 1102: 109-20. doi:10.1196/annals. 1408.008

16. Palacios G, Briese T, Kapoor V, Jabado O, Liu Z, Venter M et al. MassTag polymerase chain reaction for differential diagnosis of viral hemorrhagic fever. Emerg Infect Dis 2006; 12(4): 692-5.

17. Lipkin WI. Microbe hunting. Microbiol Mol Biol Rev 2010; 74(3): 363-77. doi:10.1128/MMBR.00007-10

18. Wang D, Coscoy L, Zylberberg M, Avila PC, Boushey HA, Ganem D et al. Microarray-based detection and genotyping of viral pathogens. Proc Natl Acad Sci USA 2002; 99(24): 15687-92. doi:10.1073/pnas.242579699

19. Palacios G, Quan PL, Jabado OJ, Conlan S, Hirschberg DL, Liu Y et al. Panmicrobial oligonucleotide array for diagnosis of infectious diseases. Emerg Infect Dis 2007; 13(1): 73-81. doi:10.3201/eid1301.060837

20. Crameri G, Todd S, Grimley S, McEachern JA, Marsh GA, Smith $\mathrm{C}$ et al. Establishment, immortalisation and characterisation of pteropid bat cell lines. PLOS ONE 2009; 4(12): e8266. doi:10.1371/journal.pone.0008266 